\title{
Synthesis and solvatochromism studies of novel bis(indolyl)methanes bearing functionalized arylthiophene groups as new colored materials
}

\author{
Elisabete Oliveira, ${ }^{a, b}$ Rosa M. F. Baptista, ${ }^{\text {C }}$ Susana P. G. Costa, ${ }^{C}$ M. Manuela M. Raposo*c and Carlos Lodeiro*a
}

The demand for dyes with solvatochromic properties has increased in the last few years, mainly due totheir wide range of applications in the analytical and industrial fields, such as in the textile industry. Thephenomenon of solvatochromism is associated with the differential solvation of the ground and excitedstates of the solvatochromic compounds, leading to an important tool for the study of the nature of solute-solvent interactions. In this paper we report the synthesis of new bis(indolyl)methanederivatives bearing arylthiophene spacers $(2 a-d)$ functionalized with electron-donating and electron-withdrawing groups, and the photophysical studies in different solvents, such as ethanol, acetonitrile,dichloromethane, trichloromethane, dimethylsulfoxide, diethylether and 1,4-dioxane. Aiming to exploretheir solvatochromic behavior in the ground and excited states, all solvents employed have differenthydrogen-bond donor abilities. The largest colour modifications were visualized for compound $2 \mathrm{~b}$, thesolution colours of which are orange in DMSO, blue in trichloromethane, green in dichloromethane andpurple in 1,4-dioxane. A negative solvatochromism was observed in $2 \mathrm{~b}$ and positive one in $2 \mathrm{a}, 2 \mathrm{c}$ and $2 \mathrm{~d}$.

\section{Introduction}

Over the years, a large number of studies have been conducted in order to discover the influence of the solvent on the chemical and physical properties of the solute. The different solvations of the ground and first excited states are associated with the solvatochromism phenomenon, which is an important tool for the study of the nature of solvent-solute interactions. Dyes with solvatochromic properties have been widely applied to investigate the solvent properties of ionic liquids ${ }^{1,2}$ and/or solvent mixtures, ${ }^{3}$ and to detect low (below $50 \mathrm{ppm}$ ) concentrations of water in aprotic solvents. ${ }^{4}$ Studies with hemicyanine dyes are very relevant due to their application in the textile industry. 5,6

The strong hydrogen-bond donor capability of the indolyl group $\mathrm{NH}$ in bis-(indolyl)methanes can lead to an internal charge transfer (ICT) state, which is responsible for a wide range of colour changes. Thus, the hydrogen bonding ability of the indolyl group can be modulated by the donor $\mathrm{H}$-atom of

${ }^{a}$ BIOSCOPE Group, REQUIMTE-CQFB, Chemistry Department, Faculty of Science and Technology, University NOVA of Lisbon Caparica Campus, 2829-516, Portugal. E-mail: ej.oliveira@fct.unl.pt, cle@fct.unl.pt; Fax: (+)34212948550

${ }^{b}$ Veterinary Science Department (CECAV), University of Trás-os-Montes and Alto Douro, 5001-801 Vila Real, Portugal.E-mail: ej.oliveira@fct.unl.pt

${ }^{c}$ Center of Chemistry, University of Minho, Campus Gualtar, 4710-057 Braga,

Portugal.E-mail:mfox@quimica.uminho.pt the solvent and other guest species. ${ }^{7}$ As an example, Wang et $a l^{8}{ }^{8}$ reported a bis-(indolyl)methene which is a colorimetric sensor for aspartate and glutamate in water. The same authors ${ }^{9}$ published a simple tris-(indolyl)methene able to detect fluoride anions, also by naked eye detection of the colour change from yellow to pink, based on proton transfer stages. Also, they reported that the introduction of an electron withdrawing or donating group at the indole moiety modified the acidity of the hydrogen bond sites, resulting in a positive effect on the sensitivity and selectivity for anions. Following our research interest ${ }^{10}$ in photophysical and photochemical studies of new emissive and chromogenic materials, herein we report the synthesis and photophysical studies of four novel bis(indolyl)methane derivatives bearing arylthiophene spacers $(2 \mathrm{a}-\mathrm{d})$ functionalized with electron-donating and electronwithdrawing groups (Scheme 1), in different solvents, such as ethanol, acetonitrile, dichloromethane, trichloromethane, dimethylsulfoxide, diethylether and 1,4-dioxane, all with different hydrogen bond donor (HBD) abilities, with the purpose of exploring their solvatochromic behaviour in the ground and excited states.

\section{Experimental section}

General synthesis

The reaction progress was monitored by thin layer chromatography $(0.25 \mathrm{~mm}$ thick precoated silica plates: Merck 
Fertigplatten Kieselgel 60 F254), while purification was effected by silica gel column chromatography (Merck Kieselgel 60; 230-400 mesh). NMR spectra were obtained using a Varian Unity Plus Spectrometer at an operating frequency of $300 \mathrm{MHz}$ for ${ }^{1} \mathrm{H}$ and $75.4 \mathrm{MHz}$ for ${ }^{13} \mathrm{C}$ or a Bruker Avance III 400 at an operating frequency of $400 \mathrm{MHz}$ for ${ }^{1} \mathrm{H}$ and $100.6 \mathrm{MHz}$ for ${ }^{13} \mathrm{C}$ using the solvent peak as an internal reference. The solvents are indicated in parentheses before the chemical shift values ( $\delta$ relative to TMS and given in ppm). Melting points were determined using a Gallenkamp apparatus. Infrared spectra were recorded using a BOMEM MB 104 spectrophotometer. Mass spectrometry analyses were performed at the "C.A.C.T.I.-Unidad de Espectrometria de Masas" at the University of Vigo, Spain.

Synthesis of bis-(indolyl)methanes $2 \mathrm{a}-\mathrm{d}$

$\mathrm{KHSO}_{4}(1.20 \mathrm{mmol})$ was added to a mixture of indole $(2.40 \mathrm{mmol})$ and formyl arylthiophene precursors $1 \mathrm{a}-\mathrm{d}$ $(1.20 \mathrm{mmol})$ in dry methanol $(10 \mathrm{ml})$, and the reaction mixture was stirred at room temperature for $7 \mathrm{~h}$. Then water $(10 \mathrm{~mL})$ was added to quench the reaction, and the aqueous phase was extracted with trichloromethane $(3 \times 20 \mathrm{~mL})$. The organic phase was dried with anhydrous $\mathrm{MgSO}_{4}$ and the crude compounds $2 \mathrm{a}-\mathrm{d}$ were purified by recrystallization from trichloromethane.

3,3'-((5'-Phenylthiophen-2'-yl)methylene)bis(1H-indole) (2a). Pink solid (87\%). Mp: 220.8-222.0 ${ }^{\circ} \mathrm{C}$. UV (acetonitrile): $\lambda_{\max }$ $\mathrm{nm}(\log \varepsilon) 292.0$ (4.60). IR (Nujol) $\mathrm{v}=3383(\mathrm{NH}), 2920,1593$, $1548,1493,1415,1335,1279,1214,1158,1119,1091,1033$, $1006,822,793,761 \mathrm{~cm}^{-1} .{ }^{1} \mathrm{H}$ NMR (DMSO- $\left.d_{6}\right) \delta=6.13(\mathrm{~s}, 1 \mathrm{H}$, $\mathrm{CH}), 6.86-6.91$ (m, 3H, 2× H-5 and H-3'), 7.01-7.08 (m, 4H, 2× H-6 and $2 \times \mathrm{H}-2), 7.21$ (t, $1 \mathrm{H}, J=7.5 \mathrm{~Hz}, \mathrm{H}-4 "), 7.30-7.36(\mathrm{~m}$, 5H, H-5", H-3", H-2", H-6" and H-4'), 7.42 (d, 2H, J=7.5 Hz, 2× $\mathrm{H}-7), 7.53$ (d, 2H, $J=8.4 \mathrm{~Hz}, 2 \times \mathrm{H}-4), 10.89(\mathrm{~s}, 2 \mathrm{H}, 2 \times \mathrm{NH}) .{ }^{13} \mathrm{C}$ NMR (DMSO- $\left.d_{6}\right) \delta=35.13(\mathrm{CH}), 111.52(\mathrm{C} 2 "$ and C6"), 117.66 ( $2 \times$ C3), 118.32 ( $2 \times$ C5), 119.07 ( $2 \times$ C7), 120.97 ( $2 \times$ C6), 122.84 (C4'), 123.35 (2× C2), 124.83 (2× C4), 125.92 (C3'), $126.28(2 \times$ C3a), 127.08 (C4"), 128.97 (C3"and C5"), 134.04 (C1"), 136.47 (2× C7a), 140.92 (C5'), $149.53\left(\mathrm{C}^{\prime}\right)$. MS (EI) m/z (\%): $404\left(\mathrm{M}^{+}\right.$, 100), 403 (36), 286 (42), 243 (27), 117 (21), 89 (10). HRMS: (EI) $\mathrm{m} / \mathrm{z}(\%)$ for $\mathrm{C}_{27} \mathrm{H}_{20} \mathrm{~N}_{2} \mathrm{~S}$; calcd 404.1347; found 404.1347.

3,3'-((5'-(4"-Methoxyphenyl)thiophen-2'-yl)methylene)bis( $1 \mathrm{H}$ indole) (2b). Dark pink solid (84\%). Mp: $150.9-152.3{ }^{\circ} \mathrm{C}$. UV (acetonitrile): $\lambda_{\max } \mathrm{nm}(\log \varepsilon) 300.0$ (4.30). IR (Nujol) $\mathrm{v}=3408$ $(\mathrm{NH}), 3053,2920,1617,1558,1505,1337,1235,1214,1151$, 1123, 1092, 1010, $743 \mathrm{~cm}^{-1} .{ }^{1} \mathrm{H}$ NMR (DMSO-d $) \delta=3.73(\mathrm{~s}$, $\left.3 \mathrm{H}, \mathrm{OCH}_{3}\right), 6.09$ (s, 1H, CH), 6.83-6.93 (m, 5H, H-3', H-3", H-5" and $2 \times \mathrm{H}-5), 6.99-7.07$ (m, 4H, 2× (H-6 and H-2)), $7.15(\mathrm{~d}, 1 \mathrm{H}$, $J=3.6 \mathrm{~Hz}, \mathrm{H}-4$ '), $7.32-7.47$ (m, 6H, H-2", H-6"and $2 \times(\mathrm{H}-4$ and $\mathrm{H}-7)), 10.87(\mathrm{~s}, 2 \mathrm{H}, 2 \times \mathrm{NH}) .{ }^{13} \mathrm{C} \mathrm{NMR}\left(\mathrm{DMSO}-d_{6}\right) \delta=35.08$ $(\mathrm{CH}), 55.13\left(\mathrm{OCH}_{3}\right), 111.51(2 \times \mathrm{C} 7), 114.35$ (C3"and $\left.\mathrm{C}^{\prime \prime}\right)$, 117.74 (2× C3), 118.29 ( $2 \times$ C5), 119.07 ( $2 \times$ C4), 120.94 (2× C6), 121.52 (C4'), 123.32 (2× C2), 125.74 (C3'), 126.19 (C2" and C6"), 126.29 (2× C3a), 126.83 (C1"), 136.46 (2× C7a), 140.98 (C5'), 148.23 (C2'), 158.49 (C4"). MS (EI) m/z (\%): $434\left(\mathrm{M}^{+}, 100\right), 401$ (10), 319 (43), 302 (21), 274 (17), 243 (34), 117 (45), 89 (19). HRMS: (EI) $\mathrm{m} / \mathrm{z}(\%)$ for $\mathrm{C}_{28} \mathrm{H}_{22} \mathrm{~N}_{2} \mathrm{OS}$; calcd 434.1453; found 434.1449.
3,3'-((5'-(4"-N,N-Dimethylaminophenyl)thiophen-2'-yl)methylene)bis(1H-indole) (2c). Green solid (42\%). Mp: 138.9-140.6 ${ }^{\circ} \mathrm{C}$. IR (Nujol) v = 3409 (NH), 3054, 2925, 1640, 1608, 1518, 1233, 1194, 1124, 1061, 1009, 957, 943, 807, $742 \mathrm{~cm}^{-1} .{ }^{1} \mathrm{H}$ NMR $\left(\mathrm{DMSO}-d_{6}\right) \delta=2.87\left(\mathrm{~s}, 6 \mathrm{H}, \mathrm{N}\left(\mathrm{CH}_{3}\right)_{2}\right), 6.07(\mathrm{~s}, 1 \mathrm{H}, \mathrm{CH}), 6.66(\mathrm{~d}$, $2 \mathrm{H}, J=9.0 \mathrm{~Hz}, \mathrm{H}-3$ " and H-5"), $6.79(\mathrm{dd}, 1 \mathrm{H}, J=3.5$ and $0.6 \mathrm{~Hz}$, H-3'), 6.88 (dt, 2H, $J=7.5$ and $0.9 \mathrm{~Hz}, 2 \times \mathrm{H}-5), 7.01-7.06(\mathrm{~m}$, $5 \mathrm{H}, 2 \times \mathrm{H}-6, \mathrm{H}-4^{\prime}$ and $\left.2 \times \mathrm{H}-2\right), 7.32-7.36$ (m, 4H, H-2", H-6" and $2 \times \mathrm{H}-7), 7.42(\mathrm{~d}, 2 \mathrm{H}, J=7.8 \mathrm{~Hz}, 2 \times \mathrm{H}-4), 10.87(\mathrm{~s}, 2 \mathrm{H}, 2 \times \mathrm{NH})$. ${ }^{13} \mathrm{C}$ NMR (DMSO- $\left.d_{6}\right) \delta=35.09(\mathrm{CH}), 39.98\left(\mathrm{~N}\left(\mathrm{CH}_{3}\right)_{2}\right), 111.51$ (C2" and C6"), 112.42 (C3"and C5"), 117.87 (2× C3), 118.28 (2× C5), 119.12 (2× C4), 119.94 (C4'), 120.94 (2× C6), 122.27 (C1"), $123.31(2 \times \mathrm{C} 2), 125.60$ (C3'), 125.76 (2× C7), 126.33 (2× C3a), 136.47 (2× C7a), 142.06 (C5'), 146.78 (C2'), 149.49 (C4"). MS (EI) $\mathrm{m} / \mathrm{z}(\%): 447\left(\mathrm{M}^{+}, 79\right), 332$ (100), 315 (25), 281 (30), 243 (23), 207 (28), 165 (22), 117 (84), 90 (35). HRMS: (EI) m/z (\%) for $\mathrm{C}_{29} \mathrm{H}_{25} \mathrm{~N}_{3} \mathrm{~S}$; calcd 447.1769; found 447.1772.

3,3'-((5'-(4"-Nitrophenyl)thiophen-2'yl)methylene)bis(1 Hindole) (2d). Orange solid $(90 \%)$. Mp: $116.5-118.0{ }^{\circ} \mathrm{C}$. UV (acetonitrile): $\lambda_{\max } \mathrm{nm}(\log \varepsilon) 370.0$ (4.17). IR (Nujol) $\mathrm{v}=3409$ (NH), 3054, 2924, 1592, 1509, 1417, 1334, 1217, 1109, 1094, $1010,851,790,745 \mathrm{~cm}^{-1} .{ }^{1} \mathrm{H}$ NMR (DMSO-d $) \delta=6.18(\mathrm{~s}, 1 \mathrm{H}$, $\mathrm{CH}), 6.90(\mathrm{dt}, 2 \mathrm{H}, J=6.8$ and $0.8 \mathrm{~Hz}, 2 \times \mathrm{H}-5), 6.99-7.02(\mathrm{~m}, 3 \mathrm{H}$, H-3' and $2 \times \mathrm{H}-6), 7.09(\mathrm{~d}, 2 \mathrm{H}, J=2.0 \mathrm{~Hz}, 2 \times \mathrm{H}-2), 7.35(\mathrm{~d}, 2 \mathrm{H}$, $J=8.0 \mathrm{~Hz}, 2 \times \mathrm{H}-7), 7.41(\mathrm{~d}, 2 \mathrm{H}, J=8.0 \mathrm{~Hz}, 2 \times \mathrm{H}-4), 7.61(\mathrm{~d}, 1 \mathrm{H}$, $\left.J=3.6 \mathrm{~Hz}, \mathrm{H}-4^{\prime}\right), 7.79$ (dd, $2 \mathrm{H}, J=7.0$ and $2.4 \mathrm{~Hz}, \mathrm{H}-2^{\prime \prime}$ and H-6"), 8.15 (dd, 2H, J = 7.0 and $2.4 \mathrm{~Hz}, \mathrm{H}-3$ " and H-5"), 10.91 $(\mathrm{s}, 2 \mathrm{H}, 2 \times \mathrm{NH}) .{ }^{13} \mathrm{C}$ NMR (acetone- $\left.d_{6}\right) \delta=36.62(\mathrm{CH}), 112.30(2 \times$ C7), 119.08 ( $2 \times$ C3), 119.57 ( $2 \times$ C5), $120.11(2 \times$ C4), $122.26(2 \times$ C6), 124.34 ( $2 \times \mathrm{C} 2), 125.05$ (C3" and C5"), 126.16 (C2" and C6"), 126.73 (C4'), 127.63 (2× C3a), 127.65 (C3'), 137.94 (2× C7a), 139.87 (C5'), 141.79 (C1"), 147.01 (C4"), 154.30 (C2'). MS (EI) m/z (\%): $449\left(\mathrm{M}^{+}, 40\right), 419$ (79), 304 (58), 243 (50), 117 (100), 90 (40). HRMS: (EI) $m / z(\%)$ for $\mathrm{C}_{27} \mathrm{H}_{19} \mathrm{~N}_{3} \mathrm{O}_{2} \mathrm{~S}$; calcd 449.1198; found 449.1197.

Spectrophotometric and spectrofluorimetric measurements of compounds $2 \mathrm{a}-\mathrm{d}$

UV/Vis absorption spectra were recorded on a Perkin Elmer lambda 45 spectrophotometer and fluorescence on a Perkin Elmer L55. The linearity of the fluorescence emission vs. the concentration was checked in the concentrations used $\left(10^{-4}-\right.$ $\left.10^{-6} \mathrm{M}\right)$. A correction for the absorbed light was performed when necessary. The photophysical characterization was performed by a stock solution of compounds $2 \mathrm{a}-2 \mathrm{~d}\left(\mathrm{ca} \cdot 10^{-3} \mathrm{M}\right)$ dissolving an appropriate amount of the compound in a $10 \mathrm{~mL}$ volumetric flask and diluting it to the mark with absolute ethanol, acetonitrile, dichloromethane, trichloromethane, dimethylsulfoxide, 1,4-dioxane and diethylether. The stock solutions were then diluted till $10^{-5}-10^{-6} \mathrm{M}$. All the measurements were performed at $298 \mathrm{~K}$. Luminescence quantum yields were measured using a solution of quinine sulphate in sulphuric acid $(0.1 \mathrm{M})$ as the standard $\left[\phi_{\mathrm{F}}=0.54\right]$.

All solvents used were of the highest purity and were from Merck. The spectroscopic polarity parameters, physical 
properties and polarity functions of the solvent used are presented in Table 1.

\section{Results and discussion}

In order to compare the effect of the electronic nature of the substituent at position 4 of the aryl moiety on the solvatochromic properties of chromophores $2 \mathrm{a}-\mathrm{d}$, formyl-derivatives containing electron-donor or electron-withdrawing groups $(\mathrm{R}=\mathrm{H}$, $\mathrm{MeO}, \mathrm{NMe}_{2}, \mathrm{NO}_{2}$ ) at the arylthienyl moiety were used as precursors. Indole and 5-phenylthiophene-2-carbaldehyde 1a were commercially available and the synthesis of 5-(4-methoxyphenyl)thiophene-2-carbaldehyde, 5-(4-( N,N-dimethylamino)phenyl)thiophene-2-carbaldehyde and 5-(4-nitrophenyl)thiophene-2-carbaldehyde $1 \mathrm{~b}-\mathrm{d}$ has been reported by us recently. ${ }^{11 a, b}$

Thus, heterocyclic probes $2 \mathrm{a}-\mathrm{d}$ with the arylthienyl moiety (bearing donor or electron-withdrawing groups) linked to the bis-(indolyl)methane system were synthesized in moderate to excellent yields (42-90\%) in methanol at room temperature for $7 \mathrm{~h}$, catalysed by potassium hydrogen sulphate (Scheme 1). ${ }^{11 \mathrm{c}}$ In the ${ }^{1} \mathrm{H}$ NMR spectra of bis-(indolyl)methanes $2 \mathrm{a}-\mathrm{d}$, a broad singlet at about 10.17-10.89 ppm was attributed to the two NH groups in the bis-indolyl moiety. The $\mathrm{NH}$ was also identified by IR spectroscopy as a sharp band within the spectral region of $3383-3409 \mathrm{~cm}^{-1}$.

Many chromophores show shifts in the absorption and emission bands in different solvents, which could be due to differences in the solvent properties such as polarity, relative permittivity and the solvent's polarization. Looking at the

Table 1 Spectroscopic polarity parameters, physical properties and polarity functions of selected solvents ${ }^{16}$

\begin{tabular}{lrlllllll}
\hline Solv. & \multicolumn{1}{c}{$\varepsilon_{\mathrm{r}}$} & $n$ & $E_{\mathrm{T}}(30)$ & $\alpha$ & $\beta$ & $\pi^{*}$ & $f(\varepsilon, n)$ & $g(n)$ \\
\hline EtOH & 24.30 & 1.36 & 51.9 & 0.86 & 0.75 & 0.54 & 0.81 & 0.24 \\
$\mathrm{CH}_{3} \mathrm{CN}$ & 35.94 & 1.34 & 45.6 & 0.19 & 0.40 & 0.66 & 0.65 & 0.23 \\
$\mathrm{CH}_{2} \mathrm{Cl}_{2}$ & 8.93 & 1.42 & 40.7 & 0.13 & 0.10 & 0.73 & 0.59 & 0.28 \\
$\mathrm{CHCl}_{3}$ & 4.89 & 1.44 & 39.1 & 0.20 & 0.10 & 0.69 & 0.49 & 0.30 \\
DMSO & 47.24 & 1.47 & 45.1 & 0.00 & 0.76 & 1.00 & 0.84 & 0.32 \\
Ether & 4.34 & 1.82 & 34.5 & 0.00 & 0.47 & 0.24 & 0.12 & 0.53 \\
Dioxane & 2.22 & 1.42 & 36.0 & 0.00 & 0.37 & 0.49 & 0.04 & 0.28
\end{tabular}

$E_{\mathrm{T}}(30)$ : Reichardt empirical polarity parameter; $\varepsilon$ : relative permittivity; $n$ : refractive index; $\alpha$ : the solvent's HBD acidity; $\beta$ : the solvent's HBA basicity; $\Pi^{*}$ : the solvent's dipolarity/polarizability.
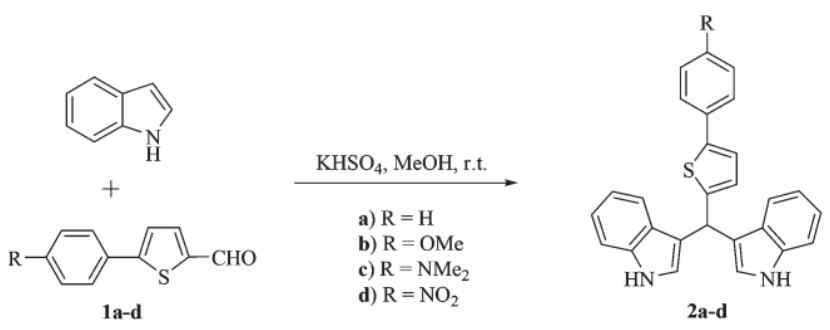

Scheme 1 Synthesis of bis(indolyl)methane derivatives 2a-d. photophysical properties of the solute, such as the dipole moment and polarization changes of the molecule in the ground and excited states, the solvent effect can offer relevant information. The dipole moment changes in the molecule in the excited state, with respect to the ground state, can be achieved by different methods based on solvatochromism (internal electric field effect). ${ }^{12,13}$ When the absorption and/or emission bands of a compound change with the solvent polarity, they are called solvatochromic. It can be either positive or negative, depending on whether a red or a blue shift is observed with the increase of the solvent polarity, respectively.

One method used for quantitatively characterizing solutesolvent interactions is the Kamlet-Taft equation, in which the absorption and emission energies are correlated with different solvent parameters by the following eqn (1):

$$
\vee 1 / 4 v_{0} \mathrm{p} a \alpha \mathrm{p} b \beta \mathrm{p} p \pi^{*}
$$

where $\mathrm{v}_{0}$ is the value of absorption and/or emission in a reference solvent; $\alpha$ : the solvent's hydrogen bond donor (HBD) acidity; $\beta$ : the solvent's hydrogen bond acceptor (HBA) basicity; $\Pi^{*}$ : the solvent's dipolarity/polarizability; and the parameters $a, b$ and $p$ (corresponding to the responses of the solute property to the solvent property) can be obtained through a multiparametric fitting.

In order to estimate the dipole moments, the absorption and fluorescence emission spectra of compounds $2 \mathrm{a}-\mathrm{d}$ were obtained in different solvents such as absolute ethanol, acetonitrile, dichloromethane, trichloromethane, dimethylsulfoxide, 1,4-dioxane and diethylether. These solvents present a dielectric constant $(\varepsilon)$ varying from 2.2 to 47.2 (see Table 1). In Table 1 , the $\alpha, \beta$ and $\pi^{*}$ parameters of all solvents tested ${ }^{16}$ are summarized.

The photophysical data, such as the maximum wavelength of absorption and emission bands, as well as the charge transfer bands of compounds $2 \mathrm{a}-\mathrm{d}$ in the studied solvents, are presented in Table 2.

Concerning the same solvent, the insertion of electrondonating $\left(\mathrm{OMe}, \mathrm{NMe}_{2}\right)$ and electron-withdrawing $\left(\mathrm{NO}_{2}\right)$ groups in compounds $2 \mathrm{~b}, 2 \mathrm{c}$ and $2 \mathrm{~d}$, respectively, induced changes in the ground and excited states ${ }^{14}$ when compared to compound 2a. Fig. 1 shows the UV/Vis absorption and emission bands of all compounds studied in acetonitrile, where a red shift is observed. In the absorption band, a value of $292 \mathrm{~nm}(2 \mathrm{a})<300 \mathrm{~nm}(2 \mathrm{~b})<325 \mathrm{~nm}(2 \mathrm{c})<370 \mathrm{~nm}(2 \mathrm{~d})$ is presented (see Table 2 and Fig. 1), with the largest band shifts being observed for compound $2 \mathrm{~d}(\Delta \lambda=78 \mathrm{~nm})$ with an electron-withdrawing group $\left(\mathrm{NO}_{2}\right)$. However, in the emission band, a value of $420 \mathrm{~nm}(2 \mathrm{a})<365 \mathrm{~nm}(2 \mathrm{~b})<400 \mathrm{~nm}(2 \mathrm{c})<450 \mathrm{~nm}$ (2d) is detected (see Table 2 and Fig. 1), with the longest shift being observed for compound $2 \mathrm{~d}(\Delta \lambda=30 \mathrm{~nm})$ with an electron-withdrawing group $\left(\mathrm{NO}_{2}\right)$. The presence of lone pairs of electrons at the oxygen and nitrogen atoms does not change the $\Pi-\Pi^{*}$ nature of the transition, but affects the energy levels of the $n-\pi^{*}$ transitions. ${ }^{14}$ The relative fluorescence quantum 
Table 2 UV/Vis absorption and emission wavelengths of 2a-d in absolute ethanol, acetonitrile, dichloromethane, trichloromethane, dimethylsulfoxide, 1,4-dioxane and diethylether

\begin{tabular}{|c|c|c|c|c|c|c|c|c|}
\hline \multirow{2}{*}{$\begin{array}{l}\text { Cpd. } \\
\text { Solv. }\end{array}$} & \multicolumn{2}{|l|}{$2 a$} & \multicolumn{2}{|l|}{$2 b$} & \multicolumn{2}{|l|}{$2 c$} & \multicolumn{2}{|l|}{$2 \mathrm{~d}$} \\
\hline & $\lambda_{\mathrm{Abs}}(\mathrm{nm})$ & $\lambda_{\text {Emis. }}(\mathrm{nm})$ & $\lambda_{\mathrm{Abs}}(\mathrm{nm})$ & $\lambda_{\text {Emis. }}(\mathrm{nm})$ & $\lambda_{\mathrm{Abs}}(\mathrm{nm})$ & $\lambda_{\text {Emis. }}(\mathrm{nm})$ & $\lambda_{\mathrm{Abs}}(\mathrm{nm})$ & $\lambda_{\text {Emis. }}(\mathrm{nm})$ \\
\hline $\mathrm{EtOH}$ & 292 & 390 & $\begin{array}{l}300 \\
430^{a}\end{array}$ & 365 & 325 & 390 & 370 & 450 \\
\hline $\mathrm{CH}_{3} \mathrm{CN}$ & 292 & 450 & $\begin{array}{l}300 \\
440^{a}\end{array}$ & 365 & 325 & 400 & 370 & 450 \\
\hline $\mathrm{CH}_{2} \mathrm{Cl}_{2}$ & 292 & 372 & $\begin{array}{l}300 \\
470^{a}\end{array}$ & 365 & 325 & 395 & 370 & 450 \\
\hline $\mathrm{CHCl}_{3}$ & $\begin{array}{l}292 \\
450^{a}\end{array}$ & 365 & $\begin{array}{l}300 \\
485^{a}\end{array}$ & 375 & $\begin{array}{l}330 \\
415^{a}\end{array}$ & 400 & 370 & 455 \\
\hline DMSO & 292 & 455 & $\begin{array}{l}300 \\
450^{a}\end{array}$ & 386 & 330 & 405 & 374 & 450 \\
\hline $\begin{array}{l}\text { Diethylether } \\
\text { 1,4-Dioxane }\end{array}$ & $\begin{array}{l}292 \\
292 \\
440^{a}\end{array}$ & $\begin{array}{l}368 \\
370\end{array}$ & $\begin{array}{l}300 \\
300 \\
520^{a}\end{array}$ & $\begin{array}{l}362 \\
363\end{array}$ & $\begin{array}{l}325 \\
320\end{array}$ & $\begin{array}{l}386 \\
386\end{array}$ & $\begin{array}{l}365 \\
370 \\
510^{a}\end{array}$ & $\begin{array}{l}450 \\
450\end{array}$ \\
\hline
\end{tabular}

${ }^{a}$ Charge transfer bands.

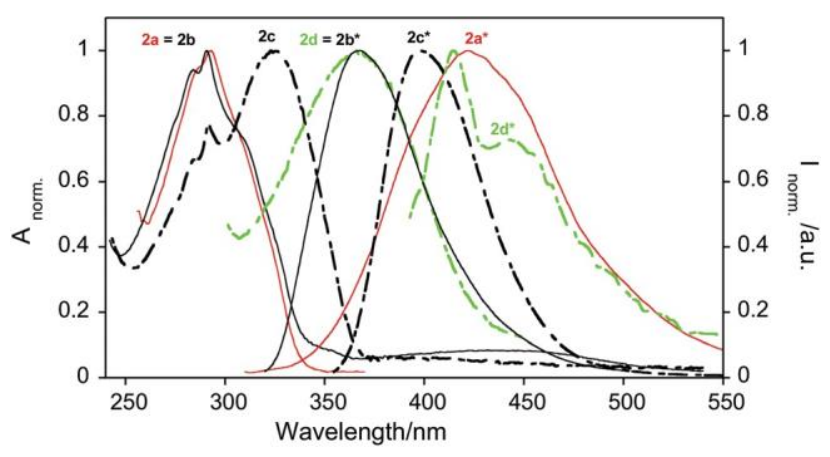

Fig. 1 UV/Vis absorption and emission spectra* of $2 \mathrm{a}, 2 \mathrm{~b}, 2 \mathrm{c}$ and $2 \mathrm{~d}$ in acetonitrile $\left([2 \mathrm{a}-\mathrm{d}]=1 \times 10^{-5} \mathrm{M}, T=298 \mathrm{~K}, \lambda_{\mathrm{exc}(2 \mathrm{a}-\mathrm{d})}=292 \mathrm{~nm}, 300 \mathrm{~nm}\right.$, $325 \mathrm{~nm}$, and $370 \mathrm{~nm}$, respectively).

yield of compounds $2 \mathrm{a}-2 \mathrm{~d}$ was measured in all solvents studied using a solution of quinine sulphate in sulphuric acid as a reference.

Fluorescence quantum yields were found to be $\mathrm{ca} . \phi=$ $0.01-0.06$ for $2 \mathrm{a}, \mathrm{ca} . \phi=0.01-0.07$ for $2 \mathrm{~b}, \mathrm{ca} . \phi=0.03-0.30$ for $2 \mathrm{c}$ and $c a$. $\phi<1 \times 10^{-3}$ for $2 \mathrm{~d}$. As can be seen, the highest values of fluorescence quantum yield were obtained for compound $2 \mathrm{c}$ with a dimethylamino group and the lowest for $2 \mathrm{~d}$ with a nitro group.

Compounds containing electron-withdrawing groups, such as $2 \mathrm{~d}$, have a low-lying $\mathrm{n}-\mathrm{T}^{*}$ excited state and thus exhibit low fluorescence quantum yields, due to a non-radiative process. ${ }^{14}$ In compound $2 \mathrm{c}$, the transitions corresponding to the promotion of an electron from an $\mathrm{n}$ orbital to a $\pi^{*}$ orbital are more intense than the $n-\pi^{*}$ transitions involving the lone pairs at the nitro group, which justifies the highest fluorescence quantum yield observed.

Concerning the different solvents, compound $2 \mathrm{a}$ shows an absorption band at ca. $292 \mathrm{~nm}$ and in apolar solvents such as trichloromethane and 1,4-dioxane a charge transfer (CT) band at $450 \mathrm{~nm}$ and $440 \mathrm{~nm}$ is observed, respectively. A colour change from colourless to yellow (1,4-dioxane) and/or orange

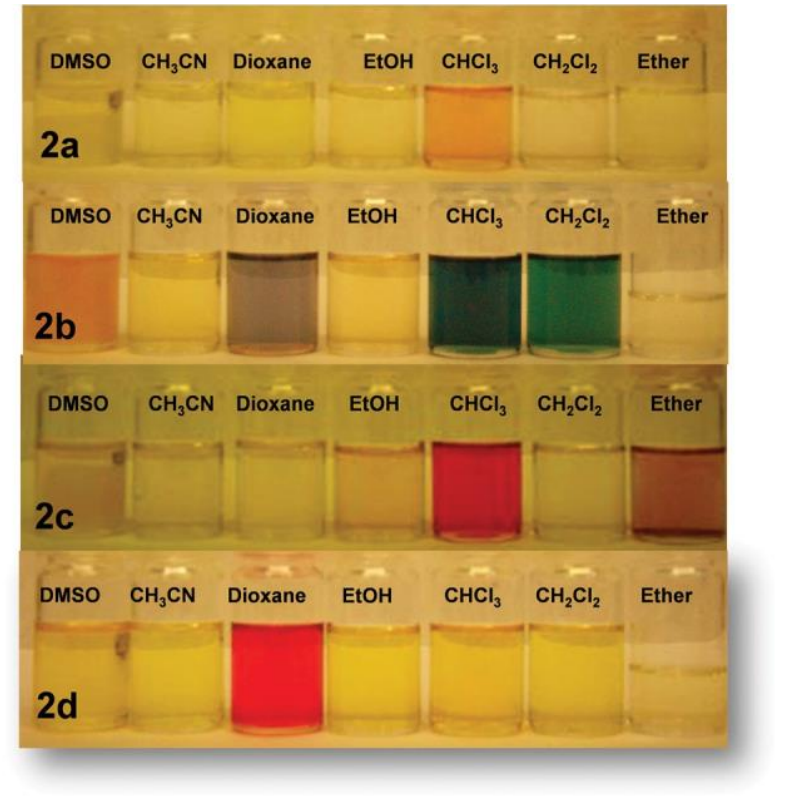

Fig. 2 Solution colours of $2 a-d$, dissolved in absolute ethanol, acetonitrile, dichloromethane, trichloromethane, dimethylsulfoxide, 1,4dioxane and diethylether $\left([2 \mathrm{a}-\mathrm{d}]=\mathrm{ca} .3 \times 10^{-4} \mathrm{M}\right)$.

(trichloromethane) is also identified (Fig. 2). In relation to the emission, a change in the maximum band from $365 \mathrm{~nm}$ (trichloromethane) to $455 \mathrm{~nm}$ (dimethylsulfoxide) could be seen (Fig. 3A and Table 2).

Compound $2 \mathrm{a}$ in the most apolar solvents has an emission band at ca. $365 \mathrm{~nm}$, and with the solvent polarity increase, a red shift in the emission band to $390 \mathrm{~nm}, 450 \mathrm{~nm}$ and $455 \mathrm{~nm}$ for ethanol, acetonitrile and DMSO, respectively, is detected. In this case a positive solvatochromism is observed (Fig. 3A).

A hypsochromic shift (blue shift) of the CT absorption bands in compound $2 \mathrm{~b}$ with the solvent polarity increase is observed, whereas the CT maximum absorption band appears 

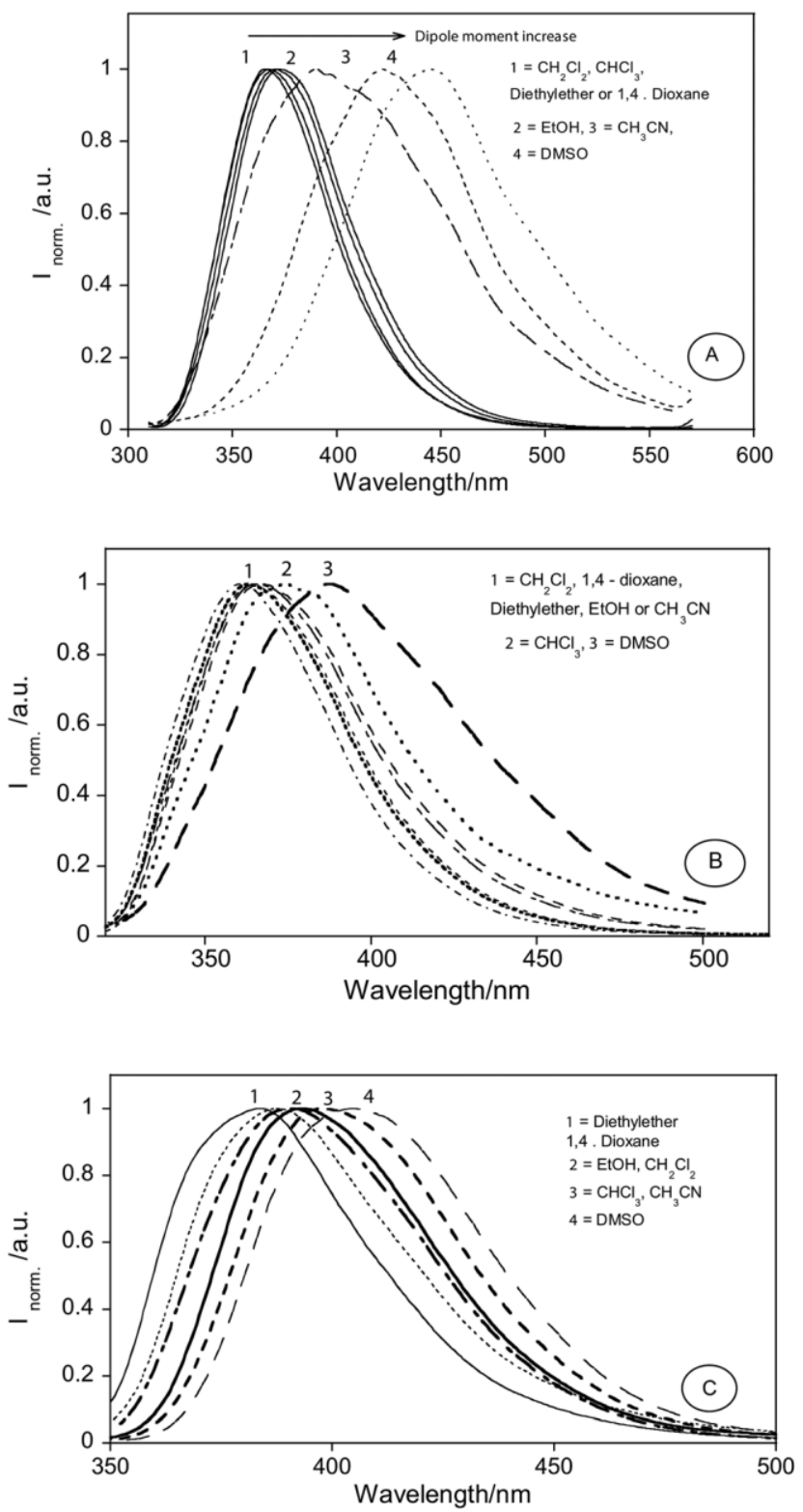

Fig. 3 Emission spectra of $2 a(A), 2 b(B)$ and $2 c(C)$ in the absolute

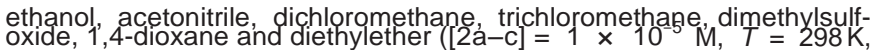

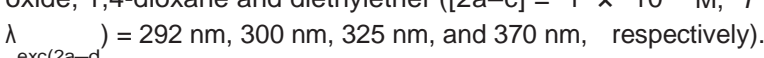

at $430 \mathrm{~nm}(\mathrm{EtOH})<440 \mathrm{~nm}\left(\mathrm{CH}_{3} \mathrm{CN}\right)<450 \mathrm{~nm}(\mathrm{DMSO})<$ $470 \mathrm{~nm}\left(\mathrm{CH}_{2} \mathrm{Cl}_{2}\right)<485 \mathrm{~nm}\left(\mathrm{CHCl}_{3}\right)<520 \mathrm{~nm}$ (1,4-dioxane).

In the emission spectrum, no relevant changes are shown, with the emission located at ca. $365 \mathrm{~nm}$ for most solvents, and $375 \mathrm{~nm}$ for trichloromethane and $386 \mathrm{~nm}$ for DMSO (see Fig. 3B). The strong modifications in the absorption of $2 \mathrm{~b}$ are also naked eye detectable, in which different colours are visualized, such as orange in DMSO, blue in $\mathrm{CHCl}_{3}$, green in $\mathrm{CH}_{2} \mathrm{Cl}_{2}$ and purple in 1,4-dioxane (Fig. 2). The negative solvatochromism for compound $2 \mathrm{~b}$ can be explained assuming that the transfer of charge in the CT excited state is antiparallel to tne grouna state, meaning tnat tne excited state nas a ıower dipole moment than the ground state. ${ }^{1 \prime}$
Compound 2c is practically not affected in the ground state with the polarity of the solvent, presenting an absorption band centered at $c a$. 325-330 nm, with the exception of trichloromethane in which a CT band at $415 \mathrm{~nm}$ and a red color is observed (Fig. 2). In the emission spectra a bathochromic shift is detected with the solvent's polarity increase, being the maximum of the emission band centered at $c a .386 \mathrm{~nm}$ (diethylether, 1,4-dioxane) < $390 \mathrm{~nm}$ (ethanol) < $395 \mathrm{~nm}$ (dichloromethane) < $400 \mathrm{~nm}$ (trichloromethane, acetonitrile) < $405 \mathrm{~nm}$ (DMSO) (Fig. 3C). Furthermore, compound 2d, in a similar manner to compound $2 \mathrm{c}$, is practically not affected in the ground state, presenting an absorption band around 365$374 \mathrm{~nm}$, as well as in the emission spectra where a weak emission is observed centered at $c a .450 \mathrm{~nm}$ in all solvents. On the other hand, in the most apolar solvent, 1,4-dioxane, it presents a CT band at ca. $510 \mathrm{~nm}$, giving a red color in this solvent (Table 2 and Fig. 2).

Overall, regarding the solvatochromic effect in the excited state (see Fig. 3), the most pronounced was observed for compounds $2 \mathrm{a}, 2 \mathrm{~b}$ and $2 \mathrm{c}$ where a red shift in the emission was obtained for $2 \mathrm{a}$ and $2 \mathrm{c}$, and a blue shift in the absorption for $2 \mathrm{~b}$, with the solvent polarity increase. Considering these results, the multiparametric fitting of the Kamlet-Taft eqn (1) was carried out using the solvent parameters listed in Table 1 for all solvents. Based on this fitting a linear plot of $\mathrm{v}_{\exp }$ versus $\mathrm{v}_{\text {calc }}$ was determined for compounds $2 \mathrm{a}-2 \mathrm{c}$; the fitted parameters are presented in Table 3 .

The $p$ values in Table 3 show that the contribution of dipolarity/polarizability decreases the stabilization of the excited state of the compounds from $2 \mathrm{c}, 2 \mathrm{a}$ to $2 \mathrm{~b}$, where $2 \mathrm{~b}$ is the most unstable and $2 c$ the most stable in the excited state. Looking at coefficient $a$, compounds $2 \mathrm{a}$ and $2 \mathrm{c}$ are less negative than $2 \mathrm{~b}$, suggesting stabilization of excited states for $2 \mathrm{a}$ and $2 \mathrm{c}$.

The dipole moments in the ground and excited states were estimated taking into account the theory of Kawski et al. ${ }^{18}$ which can be defined by: $\mathrm{v}_{\mathrm{a}}-\mathrm{v}_{\mathrm{f}}=m_{1} f(\varepsilon, n)+$ constant and $\mathrm{v}_{\mathrm{a}}+\mathrm{v}_{\mathrm{f}}=m_{2}[f(\varepsilon, n)+2 g(n)]+$ constant, whereas $\mathrm{v}_{\mathrm{a}}$ and $\mathrm{v}_{\mathrm{f}}$ are the band absorption and emission frequencies $\left(\mathrm{cm}^{-1}\right)$; $f ð \varepsilon ; n \mathrm{P}^{1 / 4} \frac{2 n^{2} \mathrm{p} 1}{n^{2} \mathrm{p} 2} \frac{\varepsilon-1}{\varepsilon \mathrm{p} 2}-\frac{n^{2}-1}{n^{2} \mathrm{p} 2 \#}$ is the solvent polarity para-

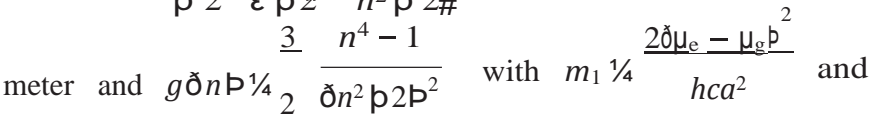
$m_{2} 1 / 4 \underline{2 \partial} \underline{\mu_{e}}-\underline{\mu_{g}} \underline{\mu}_{-}^{2}$ $h c a^{2} ; h$ is Planck's constant, $c$ the velocity of light in vacuum, $\varepsilon$ the permittivity and $n$ the refraction index, $\mu_{\mathrm{g}}$ and $\mu_{\mathrm{e}}$ the dipole moments in the ground and excited states. If the

Table $3 v_{0}, a, b$ and $p$-values, in $\mathrm{cm}^{-1}$, slope and correlation coefficients obtained from the Kamlet-Taft multiparametric fitting of the absorption (2b) and emission data (2a, 2c)

\begin{tabular}{|c|c|c|c|c|c|c|}
\hline Compound & $v_{0}\left(\mathrm{~cm}^{-1}\right)$ & $a\left(\mathrm{~cm}^{-1}\right)$ & $b\left(\mathrm{~cm}^{-1}\right)$ & $p\left(\mathrm{~cm}^{-1}\right)$ & Slope & $r^{2}$ \\
\hline $2 a$ & 25642 & -4221 & 11307 & -9573 & 1 & 0.73 \\
\hline $2 \mathrm{~b}$ & 33149 & -6436 & 1241 & -12381 & 1 & 0.87 \\
\hline $2 c$ & 27073 & -3613 & -1914 & -985 & 1 & 0.99 \\
\hline
\end{tabular}


ground and excited states are parallel, ${ }^{19}$ the dipole moment of molecules in the ground and excited states can be determined by the equations

$$
\mu_{\mathrm{g}} 1 / 4 \underline{m}_{2} \underline{m}_{2} \underline{m}_{1}^{1} \frac{h c a^{2}}{2 m_{1}}
$$

and

$$
\mu_{\mathrm{e}}{ }^{1 / 4}{\underline{m_{2}}}_{2} \underline{\mathrm{pm}} \underline{m}_{2}^{1} \frac{h c a^{2}{ }^{1 /=2}}{2 m_{2}}:
$$

The ground and excited state dipole moments for compounds $2 \mathrm{a}$ and $2 \mathrm{c}$ were determined through the linear curve fitting of $\mathrm{v}_{\mathrm{a}}-\mathrm{v}_{\mathrm{f}}$ and $\mathrm{v}_{\mathrm{a}}+\mathrm{v}_{\mathrm{f}}$ as a function of $f(\varepsilon, n)$ and $f(\varepsilon, n)+$ $2 g(n)$. The data were fitted to a straight line and the resulting slopes lead us to the $m_{1}$ and $m_{2}$ values. The dipole moments were then calculated considering the above equations and are summarized in Table 4. According to Table 4 the values of $\mu_{\mathrm{g} 2 \mathrm{a}}=$ $1.78 \mathrm{D}, \mu_{\mathrm{e} 2 \mathrm{a}}=6.82 \mathrm{D}(\Delta \mu=5.04 \mathrm{D}), \mu_{\mathrm{g} 2 \mathrm{c}}=3.60 \mathrm{D}$, and $\mu_{\mathrm{e} 2 \mathrm{c}}=$ $5.48 \mathrm{D}(\Delta \mu=1.88 \mathrm{D})$ were obtained. The values obtained indicate that compounds $2 \mathrm{a}$ and $2 \mathrm{c}$ have excited state dipole moments $\left(\mu_{\mathrm{e}}\right)$ higher than those in the ground state $\left(\mu_{\mathrm{g}}\right)$. This fact means that compounds $2 \mathrm{a}$ and $2 \mathrm{c}$ are more polar in the excited states when compared to the ground states. The higher dipole moments in the excited state could suggest the appearance of a relaxed intramolecular charge transfer (ICT) state. Such a solvent relaxation explains the increase in the red shift of the fluorescence spectrum with the solvent polarity increase. $^{14}$

Since compound $2 \mathrm{~b}$ presented a strong negative solvatochromism whereas the transfer of charge in the CT excited state is antiparallel to the ground state (the excited state has a lower dipole moment than the ground state), the dipole moments were calculated according to the Lippert-Mataga eqn (4). ${ }^{14}$

$$
\begin{aligned}
& \mathrm{v}_{\mathrm{a}}-\mathrm{v}_{\mathrm{f}} \underline{1 / 4}_{2}^{\underline{2}} h c^{\partial} \mu_{\mathrm{e}}-\mu_{\mathrm{g}} \mathrm{p}^{2} a^{-} \Delta f \mathrm{p} \text { constant } \\
& \mathrm{v}_{\mathrm{a}} 1 / 4-{ }_{2 c} \mu_{\mathrm{g}} \partial \mu_{\mathrm{e}}-\mu_{\mathrm{g}} \mathrm{Pa} a^{-} \Delta f \mathrm{p} \text { constant } \\
& \text { v } \quad \stackrel{n C}{\mu} \mu \quad \mu a^{-3} \Delta f \quad \text { constant } \\
& \mathrm{f}^{1 / 4-} h_{c} \text { e } \mathrm{g}-\mathrm{e}^{\mathrm{P}} \quad \mathrm{p}
\end{aligned}
$$

The slope from the linear regression of $v_{a}-v_{f}, v_{a}$ or $v_{f}$ as a function of $\Delta f$ gives us the dipole moment of compound $2 \mathrm{~b}$ in the ground $\left(\mu_{\mathrm{g}}\right)$ and excited $\left(\mu_{\mathrm{e}}\right)$ states and is presented in Table 4. Looking at Table 4, values of 14.5 D and 1.30 D for $\mu_{\mathrm{g}}$ and $\mu_{\mathrm{e}}(\Delta \mu=13.2 \mathrm{D})$, respectively, were obtained for $2 \mathrm{~b}$. As expected, the ground state dipole moment value is really

Table 4 Dipole moments, cavity radius and correlation factor $(r)$ of compounds $2 \mathrm{a}$ to $2 \mathrm{c}$

\begin{tabular}{lllll}
\hline Compound & Radius $(\AA)$ & $\mu_{\mathrm{g}}(\mathrm{D})$ & $\mu_{\mathrm{e}}(\mathrm{D})$ & $r^{2}$ \\
\hline 2a & 5.77 & 1.78 & 6.82 & 0.96 \\
$2 \mathrm{~b}$ & 6.12 & 14.5 & 1.30 & 0.86 \\
$2 \mathrm{c}$ & 6.03 & 3.60 & 5.48 & 0.77
\end{tabular}

higher compared with the excited state, and with the other compounds, which justifies the larger negative solvatochromism shown by compound $2 \mathrm{~b}$, as well as the strong colour changes in the different solvents studied.

\section{Conclusions}

Novel bis-indolylmethanes 2a-d bearing functionalized arylthiophene spacers were synthesized in moderate to excellent yields through a simple synthetic procedure and a simple purification methodology and completely characterised.

The solvatochromic studies showed that the largest colour modifications were visualized for compound $2 \mathrm{~b}$, whereas colours of orange for DMSO, blue for trichloromethane, green in dichloromethane and purple for 1,4-dioxane were observed. Apart from compound $2 \mathrm{~b}$, all other compounds showed a positive solvatochromism. The strong colour changes and a large negative solvatochromism in $2 \mathrm{~b}$ are in agreement with the dipole moment in the ground and excited states, whereas a value of 14.5 $\mathrm{D}$ and 1.30 $\mathrm{D}$ for $\mu_{\mathrm{g}}$ and $\mu_{\mathrm{e}}(\Delta \mu=13.2 \mathrm{D})$ was obtained. Thus, as expected, the ground state dipole moment value is really higher when compared with the excited state, and with the other compounds.

\section{Notes and references}

1 C. Reichardt, Polarity of ionic liquids determined empirically by means of solvatochromic pyridinium N-phenolate betaine dyes, Green Chem., 2005, 7,339-351.

2 C. Chiappe and D. Pieraccini, Determination of ionic liquids solvent properties using an unusual probe: the electron donor-acceptor complex between 4,4'-bis(dimethylamino)-benzophenone and tetracyanoethene, J. Phys. Chem. A, 2006, 110, 4937-4941.

3 C. Reichardt, Pyridinium N-phenolate betaine dyes as empirical indicators of solvent polarity: Some new findings, Pure Appl. Chem., 2004, 76, 1903.

4 C. Pinhero, J. C. Lima and A. J. Parola, Using Hydrogen Bonding Specific Interactions to Detect Water in Aprotic Solvents at Concentrations Bellow 50 ppm, Sens. Actuators, B, 2006, 114, 978-983.

5 C.-L. Gáspár, I. Panea and I. Bâldea, Solvent and temperature effects on the electronic transitions of 3- $H$-indolo-2dimethinehemicyanine dyes, Dyes Pigm., 2008, 76, 455-462.

6 Ullmann's encyclopedia of industrial chemistry, ed. R. Raue,

B. Elvers, S. Hawkins, G. Schulz, B. Elvers, S. Hawkins and G. Schulz, Wiley-VCH, Weinheim, 1990, vol. A16, pp. 487-534.

7 X. He, S. Hu, K. Liu, Y. Guo, J. Xu and S. Shao, Oxidized Bis(indolyl)methane: A Simple and Efficient ChromogenicSensing Molecule Based on the Proton Transfer Signaling Mode, Org. Lett., 2006, 8, 333-336.

8 L. Wang, X. He, Y. Guo, J. Xu and S. Shao, pH-Responsive chromogenic-sensing molecule based on bis(indolyl)- 
methene for the highly selective recognition of aspartate and glutamate, Beilstein J. Org. Chem., 2011, 7, 218-221.

9 L. Wang, X. He, Y. Guo, J. Xu and S. Shao, Tris(indolyl)methene molecule as an anion receptor and colorimetric chemosensor: tunable selectivity and sensitivity for anions, Org. Biomol. Chem., 2011, 9, 752-757.

10 C. Lodeiro, J. L. Capelo, J. C. Mejuto, E. Oliveira,

H. M. Santos, B. Pedras and C. Nunez, Light and colour as analytical detection tools: a journey into the periodic table using polyamines to bio-inspired systems as chemosensors, Chem. Soc. Rev., 2010, 39, 2948-2976; C. Lodeiro and

F. Pina, Luminescent and chromogenic molecular probes based on polyamines and related compounds, Coord. Chem. Rev., 2009, 253, 1353-1383; R. M. F. Batista, E. Oliveira, C. Nunez, S. P. G. Costa, C. Lodeiro and M. M. M. Raposo, Synthesis and evaluation of new thienyl and bithienyl-bis-indolylmethanes as colorimetric sensors for anions, J. Phys. Org. Chem., 2009, 22, 362-366.

11 (a) S. P. G. Costa, R. M. F. Batista, P. Cardoso, M. Belsley and M. M. M. Raposo, 2-arylthienyl-substituted 1,3benzothiazoles as new nonlinear optical chromophores, Eur. J. Org. Chem., 2006, 3938-3946; (b) R. M. F. Batista, S. P. G. Costa, M. Belsley and M. M. M. Raposo, Synthesis and optical properties of novel, thermally stable phenanthrolines bearing an arylthienyl-imidazo conjugation pathway, Dyes Pigm., 2009, 80, 329-336; (c) R. Nagarajan and P. T. Perumal, Potassium hydrogen sulfate-catalyzed reactions of indoles: a mild, expedient synthesis of bisindolylmethanes, Chem. Lett., 2004, 288-289.

12 R. Ghazy, S. A. Azim, M. Shaheen and F. El-Mekawey, Experimental studies on the determination of the dipole moments of some different laser dyes, Spectrochim. Acta, Part A, 2004, 60, 187-191.

13 J. Kabatc, B. Ósmiałowski and J. Páczkowski, The experimental studies on the determination of the ground and excited state dipole moments of some hemicyanine dyes, Spectrochim. Acta, Part A, 2006, 63, 524-531.

14 B. Valeur, Molecular Fluorescence: Principles and Applications, Wiley-VCH, Weinheim, 2001.

15 M. J. Kamlet and R. W. Taft, The solvatochromic comparison method. I. The Beta-scale of solvent hydrogen-bond acceptor (HBA) basicities, J. Am. Chem. Soc., 1976, 98, 377383; P. W. Carr, Fundamental, Predictive Approach to Dipole-Dipole Interactions Based on the Dipole Moment of the Solute and the Dielectric Constant of the Solvent,
J. Chromatogr., 1980, 194, 105-119; J. E. Brady, D. Bjorkman, C. D. Herter and P. W. Carr, Solvatochromic Investigation of Polarizable Polymeric Liquids, Anal. Chem., 1984, 56, 278-283; S. Nigam, A. de Juan, V. Cui and S. C. Rutan, Characterization of reversed-phase liquid chromatographic stationary phases using solvatochromism and multivariate curve resolution, Anal. Chem., 1999, 71, 52255234; V. Sanz-Nebot, I. Toro and J. Barbosa, Separation of potentially therapeutic peptide hormones by liquid chromatography. Optimisation of the composition and $\mathrm{pH}$ of the mobile phase, J. Chromatogr., A, 2000, 870, 335-347; Y. Zhong, Z. Jiao and Y. Yu, Simultaneous determination of mycophenolic acid and valproic acid based on derivatization by high-performance liquid chromatography with fluorescence detection, Biomed. Chromatogr., 2006, 20, 319326; M. J. Kamlet, R. M. Doherty, R. W. Taft, M. H. Abraham and W. J. Koros, Solubility properties in polymers and biological media. 3. Predictional methods for critical-temperatures, boiling points, and solubility properties (RG values) based on molecular-size, polarizability and dipolarity, J. Am. Chem. Soc., 1984, 106, 12051212.

16 J. M. Abboud and R. W. Taft, Regarding a generalized scale of solvent polarities, J. Am. Chem. Soc., 1977, 99, 83258327; M. J. Kamlet and R. W. Taft, Linear solvation energy relationships. 3. Some re-interpretations of solvent effects based on correlations with solvent pi-star and alpha values, J. Chem. Soc., Perkin Trans. 2, 1979,349-356.

17 C. Reichardt and T. Welton, Solvents and Solvent Effects in Organic Chemistry, Wiley-VCH, Weinheim, 4th edn, 2011; A. B. P. Lever, Inorganic Electronic Spectroscopy, Elsevier, Amsterdam, 1984.

18 S. Kucharski, R. Janik, H. Motschmann and C. Raduege, Trans-cis isomerization of azobenzene amphiphiles containing a sulfonyl group, New J. Chem., 1999, 23, 765-771;

A. Kawski, Progress in Photochemistry and Photophysics, Boca Raton, Boston, 1992.

19 A. Kawski, P. Bojarski and B. Kuklinski, Estimation of ground- and excited-state dipole moments of Nile Red dye from solvatochromic effect on absorption and fluorescence spectra, Chem. Phys. Lett. 2008, 463, 410-412; P. F. Barbara, P. K. Walsh and L. E. Brus, Picosecond kinetic and vibrationally resolved spectroscopic studies of intramolecular excited-state hydrogen-atom transfer, J. Phys. Chem., 1989, 93, 29-34. 